\title{
ANÁLISE DOS FRAGMENTOS FLORESTAIS URBANOS DA CIDADE DE VITÓRIA - ES
}

\author{
Samira Murelli de Souza ${ }^{12}$, Aderbal Gomes da Silva ${ }^{3}$, Alexandre Rosa dos Santos ${ }^{4}$, Wantuelfer Gonçalves ${ }^{5}$,
} Adriano Ribeiro de Mendonça ${ }^{6}$

\section{RESUMO}

Os fragmentos florestais urbanos, definidos como resquícios de vegetação natural circundados pela matriz urbana, são remanescentes da ocupação desordenada que as cidades vêm sofrendo, ao longo dos anos. O objetivo, com o presente estudo, foi realizar a análise quantitativa e mapear a distribuição dos principais fragmentos florestais urbanos presentes na cidade de Vitória-ES, utilizando geotecnologias, além de destacar a importância desses remanescentes e seus atributos, assim como, os possíveis problemas advindos dos fragmentos. Fez-se o mapeamento dos fragmentos florestais urbanos da cidade, por meio de técnicas de fotointerpretação e digitalização, na escala de 1:1.500, utilizando o aplicativo computacional ArcGIS 10. Foram identificados 146 fragmentos, compondo 937,43 ha do território de Vitória. Destes, a maioria foi representada pelos fragmentos da classe de tamanho grande (acima de um hectare). A distribuição desses fragmentos não se encontra de forma homogênea pela cidade. Os resultados evidenciaram que Vitória é uma cidade com significativa presença de fragmentos florestais em meio à urbanização. Dentre as principais importâncias, destacam-se as funções ecológicas, de lazer e estéticas, oferecidas pela cobertura vegetal.

Palavras-chave: Fragmentação florestal; Distribuição espacial; Ecologia urbana; Geotecnologia.

\section{ANALYSIS OF URBAN FOREST FRAGMENTS OF THE CITY VITORIA - ES}

\section{ABSTRACT}

The urban forest fragments, defined as remnants of natural vegetation surrounded by urban matrix, are remainings of the sprawl that cities have suffered over the years. The goal with this study was to perform quantitative analysis and distribution of the main urban forest fragments present in the city of Vitoria-ES, using geotechnology, and pointing out the importance of these remnants and their attributes, as well as the possible problems resulting of the fragments. There was made the mapping of urban forest fragments of the city through photo-interpretation techniques and scanning, on a scale of 1:1,500, using the computer software ArcGIS 10. There were identified 146 fragments, comprising 937.43 ha of the territory of Vitoria. Of these, most were represented by fragments of class size (over one hectare). The distribution of these fragments is not of homogeneous form in the city. The results showed that Vitoria is a city with a significant presence of forest fragments in the midst of urbanization. Among the main importances, were highlighted the ecological, the recreational and aesthetic functions, offered by cover vegetation.

Key-words: Forest fragmentation; Spatial distribution; Urban ecology; Geotechnology.

\footnotetext{
${ }^{1}$ recebido em 25.10.2011 e aceito para publicação em 15.03.2013

${ }^{2}$ Mestre no Programa de Pós-Graduação em Ciências Florestais da UFES - Centro de Ciências Agrárias. Avenida Governador Lindemberg, 316 - NEDTEC, Jerônimo Monteiro, ES - CEP: 29550-000. E-mail: smurellis@yahoo.com.br

${ }^{3}$ Docente do Departamento de Engenharia Florestal da UFES - Centro de Ciências Agrárias. Avenida Governador Lindemberg, 316 NEDTEC, Jerônimo Monteiro, ES - CEP: 29550-000. E-mail: aderbalsilva@yahoo.com.br

${ }^{4}$ Docente do Departamento de Engenharia Rural da UFES - Centro de Ciências Agrárias. Alto Universitário, s/nº bairro Guararema -

Alegre, ES - CEP: 29500-000. E-mail: mundogeomatica@yahoo.com.br

${ }^{5}$ Docente do Departamento de Engenharia Florestal da UFV. Avenida P. H. Rolfs, s/nº - Viçosa, MG - CEP: 36570-000. E-mail: w.goncav@ufv.br

${ }^{6}$ Docente do Departamento de Engenharia Florestal da UFES - Centro de Ciências Agrárias. Avenida Governador Lindemberg, 316 NEDTEC, Jerônimo Monteiro, ES - CEP: 29550-000. E-mail: ribeiroflorestal@yahoo.com.br
} 
O rápido crescimento urbano verificado no Brasil fez com que a ocupação das cidades ocorresse de forma desordenada. Essa urbanização vem alterando significativamente o meio ambiente, o que tem levado às condições extremas a pressão da população sobre os recursos naturais, gerando profundas mudanças no equilíbrio ambiental (MOURA-FUJIMOTO, 2000).

A cidade de Vitória, no Espírito Santo, foi sendo ocupada de forma que, com o passar dos tempos, sua extensão territorial ampliou-se em decorrência dos aterros efetuados para suportar as necessidades provocadas pelos avanços da ocupação urbana. O uso e ocupação da terra em Vitória foram acontecendo ao longo do tempo, pois esta cidade foi o centro polarizador das atividades econômicas e políticas do Estado do Espírito Santo, recebendo grande quantidade de imigrantes (VIEIRA, 2004). Com todas as transformações no ambiente, Castro (1999) ressalta que o conforto humano vem sendo ameaçado pelas alterações climáticas decorrentes das mudanças das características térmicas da superfície, das taxas de evaporação e novos padrões de circulação do ar, impermeabilização do solo, redução na quantidade de cobertura vegetal e atividades do homem. Diante deste cenário, Paula (2004) adverte que a vegetação é um fator natural que deve ser explorado para controlar os efeitos nocivos da radiação e aumentar o conforto humano dentro dos centros urbanos.

Os fragmentos florestais urbanos são resquícios de vegetação natural circundados por uma matriz urbana, que correspondem aos parques, reservas e pequenas manchas de matas em propriedades privadas. Nos ecossistemas urbanos, onde as condições naturais se encontram quase completamente alteradas e, ou, degradadas, os fragmentos representam um recurso precioso para a melhoria da qualidade de vida nas cidades, pois o uso da vegetação ameniza os impactos causados pela ação antrópica (FEIBER, 2004).

As pressões agropecuárias e imobiliárias, as práticas erradas de manejo, como a remoção de áreas florestais e queimadas, erosão, a pressão antrópica e o isolamento contribuem para a degradação acelerada e perda de diversidade natural, aumentando a fragilidade destes remanescentes florestais, fazendo com que essas áreas enfrentem difíceis condições de perpetuação. Para a gestão dos problemas ambientais nos núcleos urbanos é imprescindível o manejo correto da vegetação. Conforme Badiru et al. (2005), a inexistência de um manejo planejado ecologicamente e integrado ao ambiente urbano faz com que os fragmentos florestais urbanos se apresentem, em muitas situações, mal estruturados e desordenados.

Dessa forma, para que essas áreas cumpram suas funções ecológicas, estéticas e de lazer, e possam ser utilizadas na conservação dos recursos florestais, faz-se necessário o desenvolvimento de ações adequadas de manejo, embasadas nos estudos quali-quantitativos e distribuição espacial dessa vegetação, para que a sustentabilidade seja mantida ao longo do tempo.

Para analisar os padrões de estrutura espacial da cobertura vegetal intraurbana, têm sido utilizados Sistemas de Informações Geográficas (SIGs). O uso integrado do SIG e das imagens de satélite de alta resolução é de extrema importância em estudos de Ecologia da Paisagem, por permitirem a detecção

ANÁLISE DOS FRAGMENTOS FLORESTAIS URBANOS... 
precisa dos fragmentos remanescentes e seus estados de conservação (OLIVEIRA et al., 2008).

Segundo Alvarez (2004), os SIGs são ferramentas computacionais para geoprocessamento que permitem identificar características com precisão geográfica. Entre as técnicas relacionadas aos estudos ambientais, a fotointerpretação é um importante subsídio para tomada de decisões, pois permite identificar e caracterizar diferentes áreas por meio da interpretação dos resultados, com base em imagens de alta resolução.

Levando em consideração essas informações, objetivou-se com o presente trabalho, realizar o mapeamento e a análise quantitativa dos fragmentos florestais urbanos na malha urbana de Vitória-ES, utilizando técnicas de geoprocessamento, além de evidenciar as principais importâncias e alterações a que estão expostos os fragmentos florestais urbanos, a partir de revisão bibliográfica.

\section{MATERIAIS E MÉTODOS}

\section{Caracterização da área de estudo}

O estudo foi realizado na cidade de Vitória, capital do Estado do Espírito Santo, situada a 20¹9' de Latitude Sul e $40^{\circ} 20^{\prime}$ de Longitude Oeste. A cidade é uma das menores do território Brasileiro, com área de aproximadamente $99 \mathrm{~km}^{2}$ e população de 327.801 habitantes, conforme dados censitários do IBGE (2010).

O clima é o tropical úmido, com temperatura média anual em torno de $24^{\circ} \mathrm{C}$. A cidade de Vitória faz parte do Bioma Mata Atlântica (IBGE, 2010), representada tipicamente pela floresta tropical, áreas de mangue e restinga. Quanto ao relevo das ilhas, $40 \%$ da área da cidade são montanhosas (PREFEITURA MUNICIPAL DE VITÓRIA, 2011a), ou seja, não é possível grande expansão no local.

Vitória é dividida por oito Regiões Administrativas, compondo os 78 bairros da cidade mais a área do Aeroporto, denominadas: Região 01- Centro; Região 02- Santo Antônio; Região 03- Bento Ferreira; Região 04- Maruípe; Região 05- Praia do Canto; Região 06- Continental; Região 07- São
Pedro e, Região 08- Jardim Camburi (PREFEITURA MUNICIPAL DE VITÓRIA, 2011b).

\section{Base de dados e mapeamento dos fragmentos florestais urbanos de Vitória, ES}

O mapa representativo dos fragmentos florestais urbanos de Vitória foi obtido por meio da digitalização do ortofotomosaico do ano de 2007, da cidade em estudo, disponibilizado pelo Instituto Estadual do Meio Ambiente e Recursos Hídricos (IEMA), com escala de 1:35.000 e resolução espacial de $1 \mathrm{~m}$.

Conforme Pirovani (2010), a aerofoto IEMA 2007/2008, abrange todo o território do Estado do Espírito Santo. É fruto do convênio "VALE DE QUALIDADE AMBIENTAL” celebrado entre a Companhia VALE e o Governo do Estado, este representado pelo IEMA. As aerofotos, formadas pela articulação de cerca de 540 blocos de imagens de 10x10 km, são constituídas de imagens de alta qualidade. 
A digitalização via tela das feições foi feita na escala de 1:1.500 no aplicativo computacional ArcGIS 10, da empresa ESRI, por meio de técnicas de fotointerpretação, obtendo informações quanto às áreas ocupadas e a distribuição espacial dos elementos de interesse. Foram considerados fragmentos florestais qualquer aglomeração de árvores de grande porte, visível na aerofoto. Todas as feições capturadas na composição de imagens foram consideradas, independentemente de se tratar de vegetação natural ou plantada, uma vez que esse estudo compreende o mapeamento de fragmentos, em geral.

Foi elaborado um arquivo vetorial poligonal (shapefile) para os fragmentos identificados. O shapefile foi sobreposto à imagem da aerofoto para a digitalização via tela. Após o processo de digitalização fez-se o agrupamento dos polígonos para o cálculo das áreas dos fragmentos mapeados. Assim, foi obtido o mapa temático dos fragmentos florestais urbanos da cidade. As etapas da metodologia utilizada estão demonstradas no fluxograma a seguir, na Figura 1.

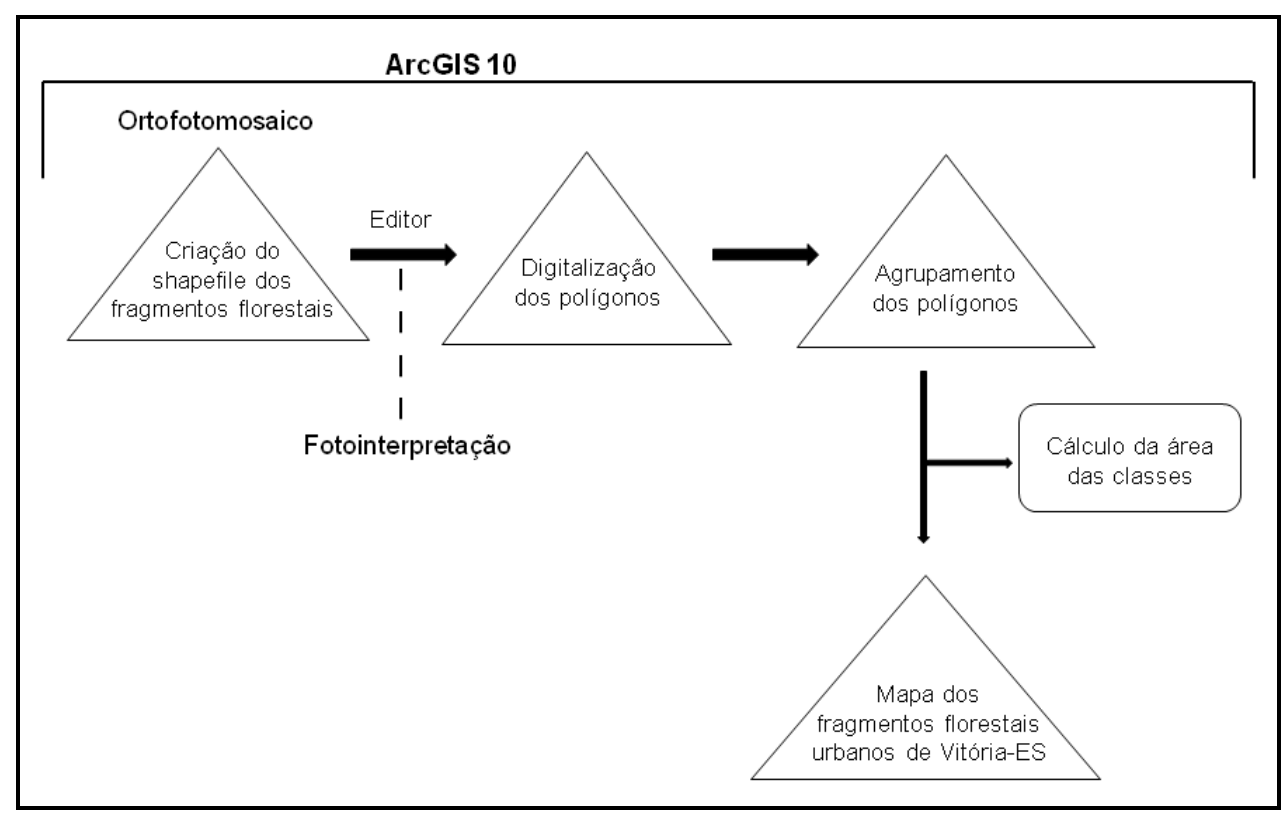

Figura 1. Etapas para elaboração do mapa de fragmentos florestais urbanos de Vitória, ES.

A quantificação da área de cada polígono foi obtida por meio da calculadora de valores da tabela de atributos do próprio arquivo vetorial, tornando possível comparar os tamanhos das áreas e as porcentagens em relação à área total de Vitória, no ano de 2007.
Salienta-se que todos os mapas exibidos neste trabalho apresentam suas coordenadas no sistema UTM, tendo sido elaborados utilizando o Datum WGS-84, zona $24 \mathrm{~K}$. 
As interpretações e a digitalização feita a partir da aerofoto mostraram que não há uma distribuição homogênea dos fragmentos pela malha urbana de Vitória, sendo que as Regiões Administrativas localizadas no setor Oeste apresentam maior quantidade de fragmentos em relação às situadas na porção Leste, conforme pode ser constatado na Figura 2. A maior preservação das matas em tais locais provavelmente está relacionada à presença de relevo mais irregular e elevado, já que a porção Leste está mais próxima da faixa litorânea, sendo, portanto, região mais plana.

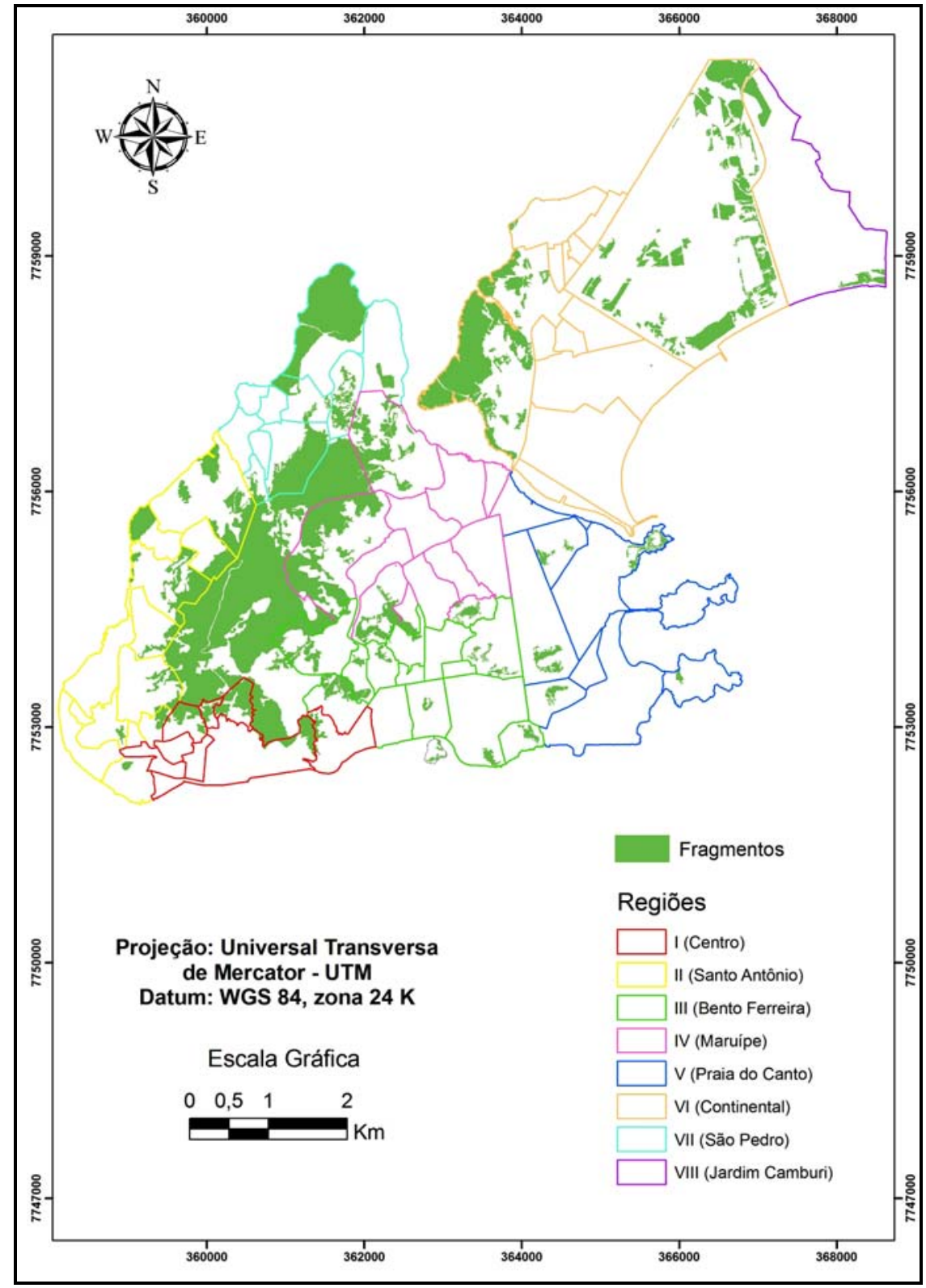

Figura 2. Distribuição dos fragmentos florestais urbanos, na cidade de Vitória-ES. 
Foram identificados pelo mapeamento, 146 fragmentos florestais urbanos, compondo ao todo, 937,43 ha. Este valor correspondeu a 10,08\% da área de estudo, uma vez que Vitória apresentou 9.300 ha de território em 2007.

Os fragmentos corresponderam às grandes áreas reflorestadas, áreas de restinga e de mangue que caracterizam a vegetação da cidade. Algumas áreas mostraram-se bastante significativas no mapeamento, como o campus da Universidade Federal do Espírito Santo (Região VI), cercado por uma extensa área de manguezal mantida sob proteção ambiental.

Outra importante área é o Maciço Central de Vitória, caracterizado pela presença do maior fragmento presente na cidade, composto por Parques Naturais protegidos, que servem como zonas de transição entre o ambiente urbano consolidado e os remanescentes naturais preservados. Este grande fragmento localiza-se especificamente, na Região I (Centro), II (Santo Antônio), III (Bento Ferreira), IV (Maruípe) e VII (São Pedro). Nota-se ainda, a presença expressiva de fragmentos nos limites do Aeroporto, localizado na Região VI (Continental).

Foi possível, também, perceber a ocorrência de algumas matas não conectadas, apontando o processo de fragmentação na distribuição dos remanescentes de florestas da região. Segundo Pirovani (2010), a fragmentação florestal é um fenômeno grave, pois os fragmentos são expostos a mudanças físicas e biogeográficas, em grande ou pequena escala, e seus efeitos dependem de variações no tamanho, forma, posição na paisagem e grau de isolamento.

Ainda assim, o mapeamento evidenciou uma cidade com significativa presença de fragmentos remanescentes do intenso crescimento territorial urbano, que Vitória vem sofrendo ao longo da história. Essa configuração poderia ser ainda melhor, porém, poucas são as áreas hoje destinadas ao reflorestamento, visando recuperar o ambiente natural que foi degradado pela urbanização. Tal fato acontece principalmente, pela limitação de espaços livres observada em Vitória, em decorrência da intensa verticalização e alta densidade demográfica. Desta forma, entende-se que a cidade de Vitória recebe muitos benefícios oriundos da vegetação dos fragmentos florestais urbanos, pois estes agrupamentos arbóreos tendem a uma maior influência no microclima, proporcionando sensação confortável, uma vez que ao “filtrarem” a radiação solar, reduzem a quantidade de energia retida pelos materiais artificiais da cidade e aumentam a umidade relativa do ar, por meio da evapotranspiração e pela maior densidade das copas das árvores.

\section{Classes de tamanho dos fragmentos florestais urbanos de Vitória}

No mapeamento foram identificados fragmentos florestais urbanos de diferentes dimensões. Dentre estes foram encontrados fragmentos grandes (acima de um hectare), fragmentos médios (0,5 a 1 hectare) e fragmentos pequenos (abaixo de 0,5 ha), representados na Figura 3.

$\mathrm{Na}$ classe de fragmentos grandes, o maior fragmento encontrado em Vitória possui 508,5 hectares e corresponde ao Maciço Central, constituído por espécies remanescentes da Mata Atlântica, que compõem o Parque Estadual da Fonte Grande, os Parques Municipais de Tabuazeiro e Gruta da Onça e a Reserva Ecológica ANÁLISE DOS FRAGMENTOS FLORESTAIS URBANOS... 
Municipal Pedra dos Olhos. Essas Unidades de Conservação em conjunto, formam a Área de Proteção Ambiental (APA) do Maciço Central; apresentam vegetação em estádios sucessionais avançados, que abriga fauna variada onde se podem observar aves, répteis e pequenos mamíferos, entre outros. A topografia é acidentada com relevo ondulado, incluindo vales e pontões. A maior preservação das matas no Maciço Central, possivelmente está relacionada ao fato de ser a área de maior altitude de Vitória (aproximadamente 300 m), pois existe uma tendência de maior ocupação urbana nas áreas mais planas. Sua localização é privilegiada, criando mirantes naturais de visualização da cidade e seu entorno.

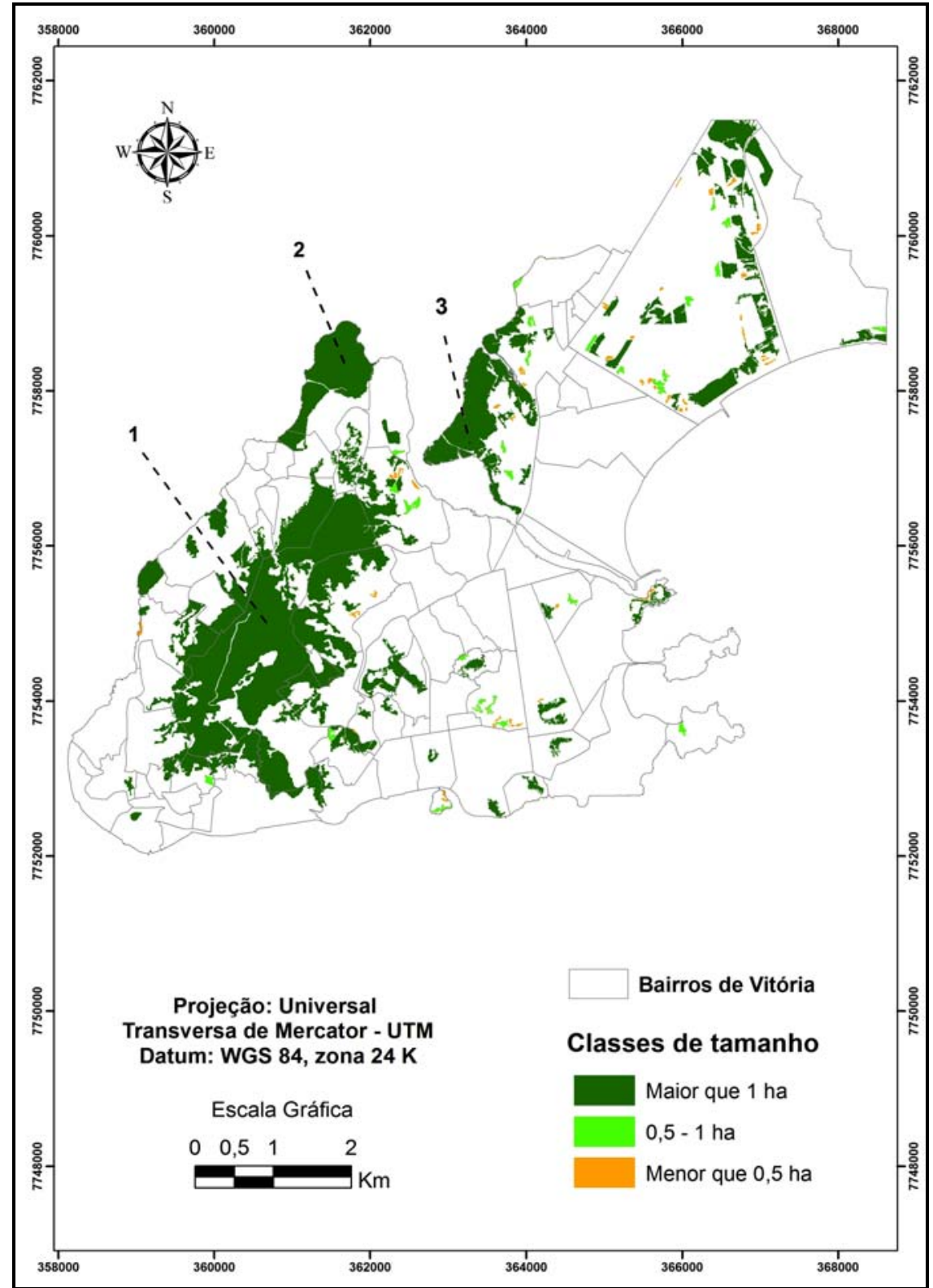

Figura 3. Classes de tamanho dos fragmentos florestais de Vitória, ES. 1-Maciço Central; 2-Ilha do Lameirão; 3Mangue da UFES. 
O segundo maior fragmento mapeado, está presente nos bairros Nova Palestina e Redenção (Região VII - São Pedro) e possui 75,3 ha. Faz parte da Estação Ecológica Municipal Ilha do Lameirão - maior área de manguezal e de mata seca de restinga do município. Segundo Tulli (2007), em Vitória os manguezais estão amparados pela Lei Municipal 3377 de 12 de Setembro de 1986, quando houve a criação dessa Estação Ecológica. A Estação foi criada com a finalidade de preservar e proteger permanentemente os ecossistemas e os recursos naturais da área, especialmente como reserva genética da flora e fauna, para fins científicos (com autorização do órgão responsável pela administração da unidade) e educacionais.

$\mathrm{O}$ terceiro maior fragmento identificado no mapeamento possui 67,06 ha e corresponde à vegetação de mangue presente nos domínios do campus da UFES, em Goiabeiras (Região VI).

Pôde-se observar no mapa que, com exceção da APA do Maciço Central, os demais fragmentos presentes na cidade apresentam-se pouco interligados. Diversos autores afirmam que uma das características desse processo é o empobrecimento dos fragmentos florestais, que passam por uma gradativa perda da diversidade biológica e diminuição das funções ecológicas (NASCIMENTO et al., 1999; AMADOR e VIANA, 2000). Sabe-se que em fragmentos pequenos e isolados, a tendência ao empobrecimento se dá devido à incapacidade de regeneração de muitas populações nessas condições (TURNER e CORLETT, 1996 citados por ARAÚJO et al., 2009).

Devido a isso, o reconhecimento das dimensões dos fragmentos torna-se um fator importante, pois matas maiores e com mais corredores de conexão têm maior capacidade de suporte à fauna e flora (CÂMARA, 1996; ZAÚ, 1998). A partir daí, encontra-se organizada na Tabela 1, a quantificação dos fragmentos existentes em Vitória, de acordo com três classes de tamanho.

Tabela 1. Quantificação das classes de tamanho dos fragmentos florestais em Vitória, ES

\section{Classes de tamanho}

Número de fragmentos
Percentual (\%)
71
28
47
A Acima de 1 ha
1
48,6
B $\quad 0,5-1$ ha
19,2
C Abaixo de 0,5 ha
32,2

\section{Total}

Fonte: SOUZA, 2011.

A classe A (grandes) representou o maior percentual (48,60\%) no número total de fragmentos identificados, seguida da classe C (pequenos) com
32,20\% e a classe B (médios), com 19,20\% do total de fragmentos mapeados. Desta forma, nota-se que os fragmentos grandes se encontram em maioria na ANÁLISE DOS FRAGMENTOS FLORESTAIS URBANOS... 
área de estudo, enquanto os fragmentos médios são os que menos prevalecem.

Estes resultados demonstram que a relação entre o número de fragmentos e a área que eles ocupam é equivalente, isto é, os grandes fragmentos possuem o maior percentual em número e representam a maior parcela da área total dos remanescentes florestais mapeados, havendo assim, maior contribuição e benefícios da vegetação na área de estudo.

\section{Importâncias dos fragmentos florestais urbanos}

Mesmo reduzidos e geralmente isolados, os fragmentos florestais são parte de um ecossistema original, detendo uma riqueza considerável de espécies vegetais, que se encarregam de abrigar e alimentar algumas espécies de animais silvestres (SANTIN, 1999; PAIVA e GONÇALVES, 2002), contribuindo na proteção da biodiversidade local.

Nos solos cobertos com vegetação ocorre elevada evapotranspiração, infiltração e pouco escoamento superficial das águas pluviais. Dessa forma, os fragmentos contribuem para a melhoria do ciclo hidrológico e na conservação do solo (MELO et al., 2011a).

As folhas e galhos das árvores atuam também como filtros, retendo parte do material particulado em suspensão no ar, sendo assim responsáveis por redução nos níveis de poluição atmosférica. As trocas gasosas ajudam a aumentar o teor de oxigênio disponível e contribuem, igualmente, na diminuição da quantidade de carbono na atmosfera, visto que durante seu crescimento esses vegetais capturam grandes quantidades desse elemento (CANDIDO e NUNES, 2010).

A beleza cênica da paisagem, bem como o lazer, incluindo atividades físicas e recreativas, também são funções dos fragmentos florestais incorporados como praças, parques urbanos e naturais. O contato com a vegetação promove bem-estar, melhorando a saúde da população e a qualidade de vida (PAIVA e GONÇALVES, 2002).

Neste sentido, o fragmento florestal do Maciço Central em Vitória, apresenta uma composição natural diversificada e extensa, que contrasta com a agitação da metrópole, e é um convite a quem deseja relaxar apreciando a natureza, além das trilhas e mirantes que oferecem visões privilegiadas para a observação da cidade.

Outra importância dos fragmentos é a econômica, que está relacionada com a geração de empregos, tendo em vista que é indispensável o manejo e a manutenção do local, sendo necessário que haja pessoas trabalhando para manter esse propósito (PAIVA e GONÇALVES, 2002).

Os fragmentos florestais urbanos são utilizados também para atividades de educação ambiental e realização de pesquisas, permitindo obter informações científicas dos ecossistemas e oferecer subsídios para a preservação e proteção ambiental. Em Vitória, o fragmento da Estação Ecológica Municipal Ilha do Lameirão oferece exclusivamente essas funções de proteção e educação, sendo vedado o uso público.

\section{Alterações sofridas pelos fragmentos florestais urbanos}

O aproveitamento dos fragmentos florestais urbanos como áreas de lazer minimiza a ação de alguns fatores de perturbação das práticas inadequadas de manejo, bem como proporciona momentos agradáveis aos cidadãos (MELO et al., 2011b). 
No entanto, a criação e a estrutura dessas áreas de lazer, sobretudo as praças distribuídas pelo território de Vitória, ao mesmo tempo em que oferecem benefícios à população, acarretam alterações significativas na fisionomia e na composição original dos fragmentos florestais, devido ao atual cenário urbano, composto em grande parte por espaços impermeáveis.

Dentre as principais alterações, tem-se: o "recorte" da mata nativa para construção de caminhos pavimentados, implantação de infraestruturas e plantio de espécies vegetais exóticas (SANTIN, 1999).

Em Vitória este cenário tornou-se comum, de acordo com estudo realizado por Souza (2011). Nele foram identificadas 35 áreas de lazer, sendo seis parques urbanos e 29 praças, excluindo-se os parques naturais voltados à preservação ambiental. Constatou-se que, em 21 dessas áreas os espaços construídos e os materiais artificiais prevaleceram em suas composições, em média de $70 \%$ em relação aos espaços destinados à vegetação. Tal situação desfavorece o contato do indivíduo com os fatores naturais.

É comum ainda encontrar nessas áreas 'playgrounds', quadras esportivas, sanitários, administração, lanchonetes, entre outras superfícies impermeáveis, o que tornam o antigo ecossistema natural em um ecossistema modificado e frágil (MELO et al., 2011a).

A APA do Maciço Central caracteriza-se por ser a área mais significativa de Vitória quanto ao porte de vegetação, conforme os dados encontrados no mapeamento da Figura 3. Os parques naturais que a compõem também funcionam como áreas de lazer, além da função principal de preservação. É notório que as praças e parques urbanos da cidade não possam ter o porte dessas Unidades de
Conservação, no entanto seria importante que tivessem mais espaços livres em seu entorno, reservados às áreas verdes e sua preservação.

Para tanto, torna-se interessante realizar zoneamentos das áreas de praças e parques urbanos, definindo as zonas de uso intensivo e restrito, de forma proporcional com o tamanho da área e a necessidade da região. Nas zonas de uso intensivo seria concentrada a sede, as áreas de recreação e demais espaços necessários, enquanto no restante haveria restrições de uso e modificações, ficando assim boa parte da área voltada para a preservação da natureza ali existente.

O zoneamento promoveria uma paisagem mais natural e mais bem distribuída por todas as regiões de Vitória. Essa solução evitaria o isolamento acentuado, com poucos e pequenos fragmentos dispersos, e muitas vezes, apenas algumas árvores isoladas nas áreas naturais que sofreram alterações para compor a cidade.

Segundo Isernhagen et al., (2009), o padrão complexo e muitas vezes desordenado de crescimento da maior parte das cidades pode levar a um aumento da heterogeneidade dos padrões na paisagem, com fragmentos dispersos e isolados. Frequentemente, o isolamento e a redução dos fragmentos, prejudicam a biodiversidade da flora e fauna, pela menor probabilidade de estabelecimento do fluxo gênico contínuo entre estes fragmentos.

Do ponto de vista ecológico, a dispersão dos fragmentos pode ser positiva, uma vez que cria mais habitats para a sobrevivência de espécies da fauna. Ao mesmo tempo, pode dificultar alguns processos biológicos naturais como deslocamentos, busca por alimentos e reprodução, podendo inclusive levar a extinções locais (ISERNHAGEN, et al., 2009).

ANÁLISE DOS FRAGMENTOS FLORESTAIS URBANOS... 
Desta maneira, o isolamento, o grau de perturbação e a inadequação das práticas de manejo são as problemáticas mais severas para a redução da diversidade biológica dos fragmentos florestais urbanos, reduzindo a qualidade ambiental da região onde se encontram.

\section{CONCLUSÕES}

Em Vitória, Espírito Santo, constatou-se uma significativa presença de fragmentos florestais urbanos, com predominância de grandes fragmentos. Em destaque está o Maciço Central formado por Parques Naturais Municipais, compostos por remanescentes do Bioma Mata Atlântica. Verificou-se também a presença de fragmentos isolados de pequeno e médio porte, que podem afetar a biodiversidade do local.

Todavia, os fragmentos florestais de diversos tamanhos e formas assumem fundamental importância para a perenidade do Bioma Mata Atlântica da cidade, detendo uma riqueza considerável de espécies vegetais e da fauna silvestre em meio à urbanização, além de inúmeras outras funções e benefícios. No entanto, muitas são as pressões sofridas por eles, que comprometem as espécies e, consequentemente, a autossustentabilidade do ecossistema modificado. Sendo assim, é essencial para a recuperação e potencialização de aspectos positivos do ecossistema ambiental de Vitória, que seja considerada a interação entre o meio urbano e a natureza, e que essa seja a mais harmoniosa possível. Atrelado a isso é fundamental a colaboração da população na preservação do local, práticas adequadas de manejo, manutenção e fiscalização da área, além da função do Poder Público na aplicação da legislação ambiental nas políticas de preservação.

\section{REFERÊNCIAS BIBLIOGRÁFICAS}

ALVAREZ, I. A.; Qualidade do espaço verde urbano: uma proposta de índice de avaliação. 209p. Tese (Doutorado) - Escola Superior de Agricultura “Luiz de Queiroz”, Universidade de São Paulo - Piracicaba, SP, 2004.

AMADOR, D. B.; VIANA, V. M. Dinâmica de “capoeiras baixas” na restauração de um fragmento florestal. Scientia Forestalis, n. 57, p. 69-85, jun. 2000.

ARAÚJO, M. H. T.; LEITE, E. C.; CHAGAS, E. P. Os fragmentos florestais urbanos do campus da unifeob (são João da boa vista - sp): uma abordagem qualitativa como proposta Para conservação e manejo. REVSBAU, Piracicaba, SP, v.4, n. 3, p.49-68, 2009. 
BADIRU, A. I.; PIRES, M. A.; RODRIGUEZ, A. M. Método para classificação tipológica da floresta urbana visando o planejamento e a gestão de cidades. Anais XII Simpósio Brasileiro de Sensoriamento remoto, Goiânia, Brasil, p. 1427-1433, 2005.

CÂMARA, I. G. Plano de ação para a Mata Atlântica. Roteiro para a conservação de sua biodiversidade. Série Cadernos da Reserva da Biosfera, Caderno n4, São Paulo, 1996. 34 p. Disponível em: <http://www.cprh.pe.gov.br/rbma/downloads/CadernosRB/n4.pdf> Acesso em: Set. 2011.

CANDIDO, D. H.; NUNES, L. H. Distribuição espacial dos fragmentos de vegetação arbórea da Região Metropolitana de Campinas: uma análise com uso de ferramentas de geoprocessamento. REVSBAU, Piracicaba, SP, v.5, n.1, p.82-105, 2010.

CASTRO, L. L. F. L. Estudo de parâmetros de conforto térmico em áreas inseridas no ambiente urbano, Campinas. 155 f., Dissertação (Mestrado em Engenharia Civil), Programa de Pós-Graduação em Engenharia Civil - Universidade Estadual de Campinas, Campinas, SP, 1999.

FEIBER, S. D. Áreas verdes urbanas imagem e uso: o caso do passeio público de Curitiba, PR. R. RA'E GA, Curitiba, n. 8, p. 93-105, out. 2004.

IBGE - Instituto Brasileiro de Geografia e Estatística. 2010. Disponível em: <http://www.ibge.gov.br/cidadesat/painel/painel.php?codmun=320530\#>. Acesso em: Jan. 2011.

ISERNHAGEN, I.; LE BOURLEGAT, J. M. G.; CARBONI, M. Trazendo a riqueza arbórea regional para dentro das cidades: possibilidades, limitações e benefícios. REVSBAU, Piracicaba, SP, v.4, n.2, p.117-138, 2009.

MELO, A. G. C.; CARVAlHO, D. A.; CASTRO, G. C.; MACHADO, E. L. M. Fragmentos florestais urbanos. Revista Científica Eletrônica de Engenharia Florestal. Garça-SP, v.17, n.1, p.58-79, Fev. 2011 a.

MELO, A. G. C.; CARVAlHO, D. A.; CASTRO, G. C.; MACHADO, E. L. M. Florística da comunidade arbóreo-arbustiva de um fragmento florestal urbano - Bosque municipal Rangel Pietraróia, Marília, SP. Revista Científica Eletrônica de Engenharia Florestal. Garça-SP, v.18, n.1, p.105-117, Ago. 2011 b.

MOURA-FUJIMOTO, N. S. V. Urbanização brasileira e a qualidade ambiental. In: SUERTEGARAY, D. M. A.; BASSO, L. A.; VERDUM, R. Ambiente e lugar no urbano: a grande Porto Alegre. Porto Alegre, RS: Editora da UFRGS, 239 p., 2000.

NASCIMENTO, H. E. M.; DIAS, A. da S.; TABANEZ, A. A. J.; VIANA, V. M. Estrutura e Dinâmica de Populações arbóreas de um fragmento de floresta estacional semidecidual na região de Piracicaba, SP. Revista Brasileira de Biologia, v. 59, n.2, p. 329-342, 1999. 
OLIVEIRA, F. S.; SOARES, V. P.; PEZZOPANE, J. E. M. et al. Identificação de conflito de uso da terra em áreas de preservação permanente no entorno do Parque Nacional do Caparaó, estado de Minas Gerais. Revista Árvore, v.32, n.5, p.899-908, 2008.

PAIVA, H. N.; GONÇALVES, W. Florestas urbanas: planejamento para melhoria da qualidade de vida. Viçosa, MG: Aprenda Fácil, 180 p., 2002.

PAULA, R. Z. R. A influência da vegetação no conforto térmico do ambiente construído. 119 f., Dissertação (Mestrado em Engenharia Civil), Programa de Pós- Graduação em Engenharia Civil - Universidade Estadual de Campinas, Campinas, SP, 2004.

PIROVANI, D. B.; Fragmentação Florestal, Dinâmica e Ecologia da Paisagem na Bacia Hidrográfica do Rio Itapemirim, ES. 121p. Dissertação (Mestrado no Programa de Pós-Graduação em Ciências Florestais) Universidade Federal do Espírito Santo, ES. 2010.

PREFEITURA MUNICIPAL DE VITÓRIA. Dados Geográficos. Disponível em: <http://legado.vitoria.es.gov.br/regionais/geral/geograficos.asp> Acesso em: Jul. 2011a.

PREFEITURA MUNICIPAL DE VITÓRIA. Regiões Administrativas da cidade de Vitória. Disponível em: $<$ http://legado.vitoria.es.gov.br/regionais/geral/territorializacao.asp>. Acesso em: Jan. 2011 b.

SANTIN, D. A. A vegetação remanescente do município de Campinas (SP): mapeamento, caracterização fisionômica e florística, visando a conservação. 502 p. Tese (Doutorado em Ciências Biológicas) Universidade Estadual de Campinas, SP. 1999.

SOUZA, S. M. Mapeamento e avaliação da vegetação urbana da cidade de Vitória - ES, utilizando geotecnologias. 127p. Dissertação (Mestrado no Programa de Pós-Graduação em Ciências Florestais) Universidade Federal do Espírito Santo, ES. 2011.

TULLI, L. M. A. Vulnerabilidade à ação antrópica e uso e ocupação do solo para a estação ecológica municipal Ilha do Lameirão, Vitória-ES. 106p. Dissertação (Mestrado no Programa de Pós-Graduação em Engenharia Ambiental) - Universidade Federal do Espírito Santo, ES. 2007.

VIEIRA, F. C. S. Evolução temporal do uso e ocupação do solo para os anos de 1994 e 2002 no município de Vitória, ES, utilizando imagens orbitais do satélite Landsat TM. Monografia (Departamento de Geografia) - Universidade Federal do Espírito Santo, ES. 2004.

ZAÚ, A. S. Fragmentação da Mata Atlântica: aspectos teóricos. Floresta e ambiente, Rio de Janeiro, v.5, nº1, p. 166-170. 1998.

Samira Murelli de Souza et al.. 